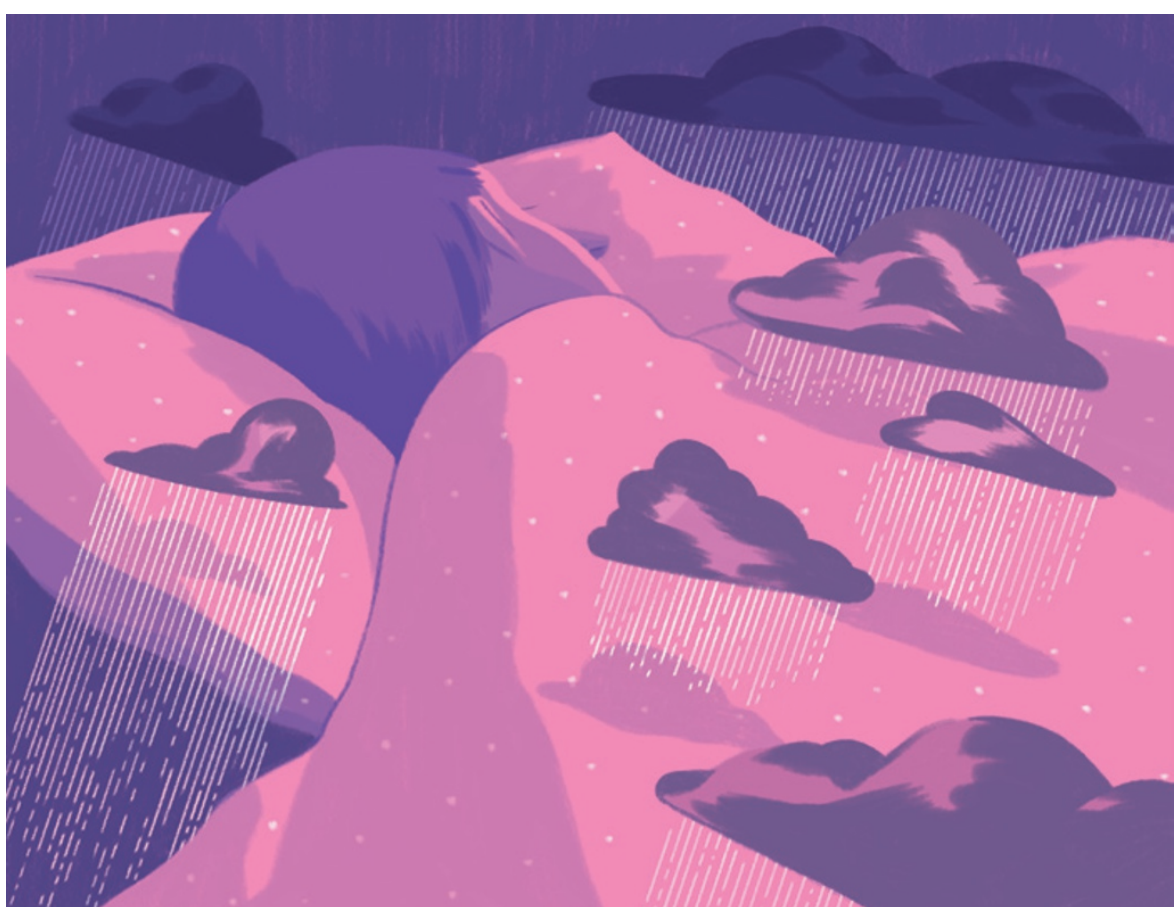

METEOROLOGY

\title{
The brainstormers
}

\section{Alan Thorpe enjoys a hymn to some of the founders of the science and institutions of weather forecasting.}

\section{$\mathrm{I}$} t is thanks to the efforts of an international community of meteorologists and atmospheric scientists that accurate forecasts of major weather systems can be made reliably up to about a week ahead (see P. Bauer et al. Nature 525, 47-55; 2015). Many researchers contributed to the revolution in weather sciences in the first half of the twentieth century, so it is perhaps invidious to single out a few.

Science historian James Fleming focuses on three: Norwegian Vilhelm Bjerknes, Swede Carl-Gustaf Rossby and American Harry Wexler. The first two I expected; the third I was intrigued to learn more about. Fleming devotes about 60 pages to each man's life and work, and mentions many others and their impacts, mostly on US weather forecasting.

To the cognoscenti, the essentials of Bjerknes's and Rossby's science will be familiar. Fleming's fascinating account clarifies why these two were giants of leadership. Bjerknes created the 'Bergen school' of meteorology, which used rigorous scientific principles to understand and predict the evolution of weather features such as fronts and cyclones. The school included his son Jacob among many talented, mainly Scandinavian, scientists. Rossby established university schools of meteorology in Stockholm and Chicago, and at the Massachusetts Institute of Technology in Cambridge. The breadth of Wexler's role emerges through his contributions to the development of techniques and operational weather forecasting, particularly in the United States.

Between the birth of Bjerknes - the oldest - in 1862 and the death of Wexler, the youngest, in 1962, there passed a formative and innovative century. As Fleming reveals, their lives were linked, with Bjerknes teaching Rossby and Rossby, Wexler.

In 1904, in 'Weather forecasting as a problem in mechanics and physics', Bjerknes set the agenda for applying the laws of physics to the atmosphere to predict the weather (V. Bjerknes Meteorol. Z. 21, 1-7; 1904). His vision was to use a sufficiently accurate knowledge of the state of the atmosphere and the laws that govern its evolution to forewarn people about weather to come. His motivation was to make his mark in what was for him a new field of science - he began his career working with his father, a physicist at the University of Oslo, on fluid analogies for the electromagnetic field. He was eager, too, to provide practical advice on hazards that affected mariners, farmers and the public.

Fleming notes the absence of a book-length biography of Rossby, and I hope that this will be rectified soon. To me, he is a first among equals. As well as building institutions, he established important principles, such as the conservation of potential vorticity - used to understand the development of rotation in cyclones and other weather systems - and the large-scale atmospheric wave patterns named after him. He was a leader in developing techniques such as experiments that simulate the atmosphere in a rotating tank of water, as well as aircraft soundings and the use of radiosondes, or radio-based measurements using weather balloons. A polymath with a high public profile, he was pictured on the cover of Time magazine in December 1956, with the title "Weatherman".

Wexler's contributions include making the first research flight into a hurricane, using radar to track storm systems, working
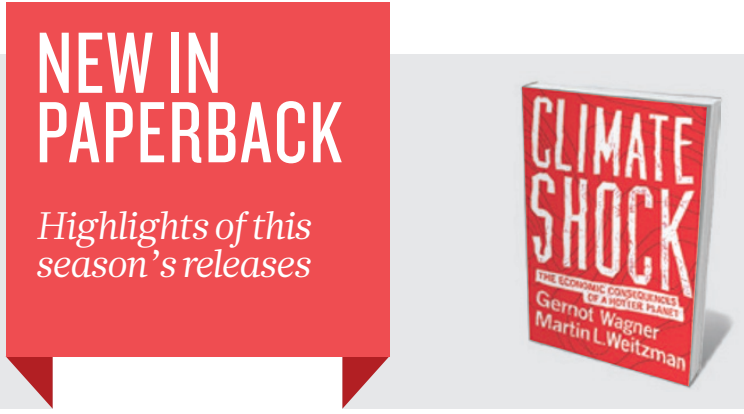

Climate Shock: The Economic Consequences of a Hotter Planet

Gernot Wagner and Martin L. Weitzman (Princeton University Press, 2016)

Global, long-term, irreversible, uncertain: four words used by economists Gernot Wagner and Martin Weitzman in their timely warning on the impacts of climate change. It is not enough to simply hope that we are wrong about worst-case scenarios; the authors' most extreme predictions include a 20-metre sea-level rise and average global temperatures reaching $6^{\circ} \mathrm{C}$ above pre-industrial levels. Wagner and Weitzman urge us to act now to insure Earth against uncertainty. 
towards space observations and developing the use of computers in meteorology.

From the findings of these three men, Fleming expertly weaves a tapestry of broader developments, from early uses of computers and satellites to numerical predictions with supercomputers. He explores intentional weather modification, radioactive fallout, rocketry, air pollution and electromagnetism. For example, the air movements made apparent when researchers tracked the fallout from nuclear-bomb tests in the 1950 s provided insight into atmospheric circulation.

The penultimate chapter covers what Fleming calls the birth of atmospheric science in the late 1950s, coinciding with planning for the International Geophysical Year in 1957-58. In 1956, Rossby proposed enlarging the definition of meteorology to include elements such as atmospheric chemistry and relevant biological processes. Much of what we regard as contemporary developments, such as the understanding of atmospheric composition or geoengineering, were in the minds of 1950s researchers, Fleming points out.

Modifying the reflectivity of the planet to avoid harmful climate change was discussed by Wexler and others as early as 1958. In a 1962 speech, Wexler said: "We are in weather control now whether we know it or not." Fleming also focuses on the importance of committees in planning developments such as the creation of the US National Center for Atmospheric Research in 1960, and the role of top researchers in leading these committees.

A historical account has to have boundaries, and Fleming barely hints at what came after 1960. I found the discussion of Edward Lorenz's work on chaos that led to aspects of probabilistic forecasting disproportionately brief.

What shines through Inventing Atmospheric Science is the commitment of three men to applications of research to society, and their desire to advance our understanding of weather. This is an inspirational story, very well told..

\footnotetext{
Alan Thorpe is visiting professor of meteorology at the University of Reading, UK. e-mail:alan.thorpe@gmx.com
}

\section{Oilman at the peak}

\section{Gregor Macdonald applauds a biography of prescient geologist and energy theorist Marion King Hubbert.}

A scientist's work does not always intersect neatly with the events of their time, but that was the good fortune of US geologist and oilman Marion King Hubbert (1903-89). After labouring for decades to perfect forecasting of the oilproduction limit, he saw his efforts validated in the energy crises of the early 1970s. His approach would later be known as Hubbert peak theory.

Journalist Mason Inman's meticulous biography The Oracle of Oil follows Hubbert from his youth on the plains of Texas through the Great Depression, the Second World War and the rise of US President Ronald Reagan in 1981. But its scope is much more expansive. In Hubbert's story, Inman has found a meditation on the booms and busts that marked twentieth-century economic growth. Hubbert's iconoclastic career forms a perfect arc, from oil's troubling oversupply in the 1920 s to its relative scarcity after the peak of US production in 1971, when the US economy suffered oil shocks.

As Inman shows, Hubbert's impact extends beyond oil: it is an early manifestation of ecological economics. At the end of his career, Hubbert remained concerned about nuclear waste; was convinced that high rates of growth were environmentally destructive; and conjectured that solar power might be the most viable energy solution. With regard to growth or sustainability, Hubbert's work is an overlooked contribution to US economic history.

Arriving at the University of Chicago in Illinois in 1924 with little money but no

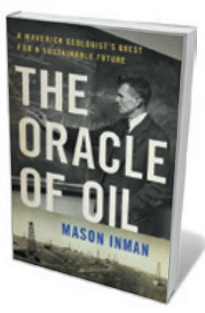

The Oracle of Oil: A

Maverick Geologist's Quest for a Sustainable Future MASON INMAN W. W. Norton: 2016

shortage of ambition, Hubbert saw geology as a wide-open field, and gate-crashed it. With precocious brilliance, he began to identify gaps and disorganization in its practices, and published his first paper, on fault classifications, as an undergraduate. In 1930, he was head-hunted by Columbia University in New York City to direct a new effort in geophysics. Here, Inman's biography reveals its thoughtful design, tracing the youthful roots of Hubbert's formidable achievements. The undergrad pondering Earth's folds one summer later becomes a breakthrough geologist, solving complex scaling problems. The boy surrounded by oil rigs becomes a Shell executive, aggressively pursuing the hydrological and structural complexities of oilfield exploration. The young man who questioned religious faith becomes a nonconformist US Geological Survey (USGS) researcher, insisting that popular forecasts are built less on data than on optimism.

Inman's direct, explanatory style is well suited to describing the evolution of Hubbert's thinking. At Columbia, Hubbert began to ponder the S-curve of growth that has long fascinated observers of economies, biology and natural-resource extraction. He perfected his technique over decades, from rough

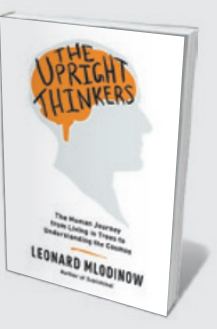

The Upright Thinkers Leonard Mlodinow (Vintage, 2016) Carrier pigeons once toted stock prices. Today, instant messaging manages the job. Theoretical physicist Leonard Mlodinow explores how the most human of desires, a thirst for knowledge, grew from Neanderthal hunger pangs to measuring our planet's orbit around the Sun.

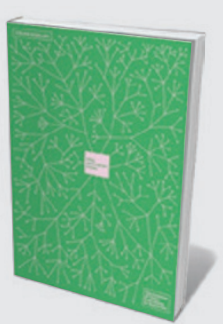

Why Information Grows

César A. Hidalgo (Penguin, 2016)

Economies are computers and information is at war with entropy, claims statistical physicist César Hidalgo. He shows how the scientific imagination needs knowledge and resources to grow, such as the Chilean copper that 'feeds' electronics (see Philip Ball's review: Nature 521, 420-421; 2015). 